\title{
Insect Pathogenic Properties of Serratia marcescens. Passive and Active Resistance to Insect Immunity Studied with Protease-deficient and Phage-resistant Mutants
}

\author{
By CASPER FLYG* AND KLEANTHIS G. XANTHOPOULOS \\ Department of Microbiology, University of Stockholm, S-106 91 Stockholm, Sweden
}

(Received 17 March 1982; revised 18 July 1982)

\begin{abstract}
Many insects have a cell-free immune system in which small basic proteins called cecropins are the main defence against Gram-negative bacteria. We have earlier shown that an insect pathogenic strain of Serratia marcescens was resistant to insect immunity and that certain mutants resistant to phage $\phi \mathrm{J}$ become sensitive to cecropins. We have found that proteasedeficient mutants with and without resistance to $\phi \mathrm{J}$ appear to be deficient in the mechanism of protease induction. Three different protease fractions exist and for two of the enzymes we describe a partial purification and characterization. The proteases show pronounced autodegradation which increases with the purity. Both enzymes are only partly affected by EDTA and they are highly toxic to Drosophila melanogaster. All three enzymes destroy cecropins in immune haemolymph from Cecropia pupae. However, in vivo experiments with different mutants indicate that in Serratia, passive resistance to insect immunity is more important for virulence in Drosophila than the production of proteases which can destroy cecropins.
\end{abstract}

\section{INTRODUCTION}

Serratia marcescens is a well known insect pathogen which can produce several hydrolytic enzymes (e.g. proteases and a chitinase), some of which have been shown to be toxins (Grimont \& Grimont, 1978; Poinar et al., 1979; Ourth \& Smalley, 1980; Blazevic, 1980). Serratia strains isolated from insects often produce more proteolytic enzymes than do wild isolates from other sources (Miyata et al., 1970; Decedue et al., 1979). A partly purified, extracellular protease from S. marcescens was shown to be toxic to an insect (Kaška, 1976). However, besides toxin production, passive resistance to insect immunity is an important virulence factor of $S$. marcescens (Flyg et al., 1980). Spontaneous mutants with decreased passive resistance can be isolated by selecting for resistance to phage $\phi \mathrm{J}$.

Using mutagens and phage $\phi \mathrm{J}$, we have now isolated a set of mutants with low levels of proteolytic enzyme activity with and without passive resistance to insect immunity. These strains were compared for their resistance to immune haemolymph from pupae of Hyalophora cecropia and also for their virulence to adult Drosophila melanogaster. A partial purification of two different proteolytic enzymes is reported, but autodigestion prevented homogeneous preparation.

\section{METHODS}

Parental strain, phage and growth media. All mutants described in this paper are descendants of strain Db11, a spontaneous streptomycin-resistant mutant of Serratia marcescens Db10 isolated from a culture of diseased Drosophila melanogaster (Flyg et al., 1980). Strain Db11 is sensitive to bacteriophage $\phi \mathrm{J}$. The growth medium was normally the LB medium of Bertani (1951). LA agar plates (LB medium with $1.5 \%$ agar) were also used. For

\footnotetext{
Abbreviations: IH, Immune haemolymph; PMSF, phenylmethylsulphonyl fluoride; RAC, remaining active concentrate.
} 
Table 1. Strains of Serratia marcescens used and their properties

\begin{tabular}{|c|c|c|c|c|c|c|c|c|c|}
\hline \multirow[b]{2}{*}{ Strain } & \multirow{2}{*}{$\begin{array}{c}\text { Parental } \\
\text { strain }\end{array}$} & \multirow{2}{*}{$\begin{array}{c}\text { Doubling } \\
\text { time* } \\
\text { (min) }\end{array}$} & \multicolumn{3}{|c|}{ Response to: $\dagger$} & \multicolumn{2}{|c|}{$\begin{array}{l}\text { Protease } \\
\text { production }\end{array}$} & \multirow[b]{2}{*}{ Comments } & \multirow[b]{2}{*}{ References } \\
\hline & & & Str & $\phi \mathrm{J}$ & IH & Prot. 1 & Prot. 2 & & \\
\hline Db10 & - & 37 & s & $\mathrm{s}$ & $\mathbf{R}$ & + & + & $\begin{array}{l}\text { Isolated from } \\
\text { diseased Drosophila }\end{array}$ & $\begin{array}{l}\text { Flyg et al. } \\
(1980)\end{array}$ \\
\hline Db1l & Db10 & 45 & $\mathbf{R}$ & $\mathbf{s}$ & $\mathbf{R}$ & + & + & & $\begin{array}{c}\text { Flyg et al. } \\
(1980)\end{array}$ \\
\hline Db1109 & Db11 & 50 & $\mathbf{R}$ & $\mathbf{R}$ & $\mathbf{s}$ & + & + & $\begin{array}{c}\text { Spontaneous } \\
\phi^{\mathrm{R}} \text { mutant }\end{array}$ & $\begin{array}{l}\text { Flyg et al. } \\
(1980)\end{array}$ \\
\hline Db1120 & Dbl1 & 44 & $\mathbf{R}$ & $\mathrm{s}$ & $\mathbf{R}$ & - & + & NG-treated & This paper \\
\hline Db1121 & Db1120 & 49 & $\mathbf{R}$ & $\mathrm{s}$ & $\mathbf{R}$ & - & + & EMS-treated & This paper \\
\hline Db1140 & Dbl121 & 51 & $\mathbf{R}$ & $\mathbf{R}$ & HS & - & + & $\begin{array}{l}\text { Spontaneous } \\
\phi \mathrm{J}^{\mathrm{R}} \text { mutant }\end{array}$ & This paper \\
\hline
\end{tabular}

* Doubling time was recorded for liquid cultures grown in LB medium in a rotatory shaker at $37^{\circ} \mathrm{C}$.

$\dagger$ Sensitivity (s), high sensitivity (HS) or resistance (R) to streptomycin (Str), phage $\phi \mathrm{J}$ and immune haemolymph from Cecropia (IH).

protease induction the C-A medium of Castañeda-Agulló (1956) was used, as modified by Bromke \& Hammel (1979) with gelatin as the protease-inducing protein. This medium was here supplemented with $10 \%$ sterilefiltered normal Cecropia haemolymph to resemble conditions in in vivo experiments. The growth rates for strains $\mathrm{Db} 11, \mathrm{Db} 1109, \mathrm{Db} 1120$ and Db1 121 were approximately the same in this C-A haemolymph medium. All strains were stored frozen at $-70^{\circ} \mathrm{C}$ in $\mathrm{LB}$ medium containing $25 \%(\mathrm{v} / \mathrm{v})$ glycerol.

Isolation of mutants. Washed cells of Dbl1 (about $3 \times 10^{8} \mathrm{ml}^{-1}$ ) were incubated at $37^{\circ} \mathrm{C}$ for $30 \mathrm{~min}$ in $0.1 \mathrm{M}$ citrate buffer, pH 5.5, containing $N$-methyl- $N^{\prime}$-nitro- $N$-nitrosoguanidine $\left(250 \mu \mathrm{g} \mathrm{ml}^{-1}\right.$; Aldrich Chemical Co., Milwaukee, Wis., U.S.A.). After washing twice with $0 \cdot 1 \mathrm{M}-\mathrm{K}_{2} \mathrm{HPO}_{4} / \mathrm{KH}_{2} \mathrm{PO}_{4}$ buffer $\mathrm{pH} 7 \cdot 0,0 \cdot 1 \mathrm{ml}$ bacterial suspension was added to $5 \mathrm{ml} \mathrm{LB}$ medium and allowed to grow overnight at $37^{\circ} \mathrm{C}$. Appropriate dilutions were spread on skim-milk plates which contained $10 \%(\mathrm{w} / \mathrm{v})$ skim-milk powder and $2 \cdot 8 \%(\mathrm{w} / \mathrm{v})$ nutrient agar (Oxoid). After $15-40 \mathrm{~h}$ at $37^{\circ} \mathrm{C}$, colonies were selected which had no detectable, or only small, clearing zones. One such clone was, after purification, designated Dbl120. To decrease the proteolytic activity further, Dbl120 was subjected to a second mutagen treatment.

An overnight culture of Dbl120 (about $2 \times 10^{9} \mathrm{ml}^{-1}$ ) was used as inoculum for approximately $100 \mathrm{~min}$ of growth in fresh LB medium, with $1 \%(w / w)$ ethylmethane sulphonate at $37^{\circ} \mathrm{C}$. After about two doublings, ethylmethane sulphonate was removed by four washings. The cells were then incubated for $120 \mathrm{~min}$ in $30 \mathrm{ml} \mathrm{LB}$ medium, spread on skim-milk plates and again screened for colonies without clearing zones. One mutant clone, Db1 121, was retained for further studies. A spontaneous mutant resistant to $\phi \mathbf{J}$ was isolated from Db1121. The procedure used for the isolation of this strain, Db1140, was the same as for Db1109 (Flyg et al., 1980). Strains Db1 109 and Db1140 are as resistant to Penicillin G as the parental strain Db11. A summary of all the Serratia strains used is given in Table 1 .

Insects, immune haemolymph and toxicity tests. Immune haemolymph (IH), containing cecropins and other immune proteins, was obtained from diapausing pupae of Hyalophora cecropia immunized with live Enterobacter cloacae (Boman \& Steiner, 1981). The assay for the antibacterial activity in the haemolymph followed the procedure of Boman et al. (1974) except that the haemolymph concentration was raised to $90 \%$.

Drosophila melanogaster strain KAS 60 (wild-type), was grown and maintained on an autoclaved corn-yeast agar substrate at $25^{\circ} \mathrm{C}, 65 \%$ relative humidity and $15.5 \mathrm{~h} \mathrm{light} / 8.5 \mathrm{~h}$ dark conditions. In all experiments male flies less than $5 \mathrm{~d}$ old were used. For immunization, the flies were injected with living Enterobacter cloacae attenuated by freeze-thawing. The concentration was $10^{9}$ cells $\mathrm{ml}^{-1}$ in $0.9 \% \mathrm{NaCl}$, according to Boman et al. (1972).

Injection experiments (i.e. toxicity tests including $\mathrm{LD}_{50}$-determinations) were performed according to the methods of Flyg et al. (1980). The Ringer solution for injections of flies contained $25 \mathrm{mg} \mathrm{KCl}, 30 \mathrm{mg} \mathrm{CaCl}, 650 \mathrm{mg}$ $\mathrm{NaCl}$ and $20 \mathrm{mg} \mathrm{NaHCO}$ in $100 \mathrm{ml}$ water. The solution was sterile-filtered after adjusting the pH to $6 \cdot 3$ by passage of $\mathrm{CO}_{2}$.

Preparative growth and harvest of cultures. Cultures of 2.51 each, were well aerated by using flasks of 41 volume on a rotatory shaker ( 90 r.p.m., amplitude $2 \mathrm{~cm}$ ). After $4 \mathrm{~d}$ growth at $37^{\circ} \mathrm{C}$, the cultures were centrifuged at $15000 \mathrm{~g}$ for $30 \mathrm{~min}$. This step and all the following parts of the purification procedure were performed at $0-4{ }^{\circ} \mathrm{C}$. The supernatants with the proteases were filtered through a pack of filters on vacuum. The pack consisted of (from the top) Whatman GF/D 2.2 $\mathrm{m}, \mathrm{GF} / \mathrm{A} 1.6 \mu \mathrm{m}, \mathrm{GF} / \mathrm{B} 1.0 \mu \mathrm{m}$ (Whatman), Gelman 0.2 $\mu \mathrm{m}$ (Gelman Instrument Co., Mich., U.S.A.). This was necessary because $4 \mathrm{~d}$ old Serratia cultures are turbid even after centrifugation, presumably due to remaining cell wall fragments. This may also explain why filters sometimes become clogged. As 
purity controls, cultures were streaked on LA plates with streptomycin $\left(100 \mu \mathrm{g} \mathrm{ml}^{-1}\right)$ and tested for sensitivity to phage $\phi \mathbf{J}$ (Flyg et al., 1980).

Concentration, gel filtration and ion exchange chromatography. Filtrates were concentrated with an Amicon concentrator and Diaflo hollow fibres (Amicon Corp. Sci. Div. System, Mass., U.S.A.). When volumes had decreased to less than $200 \mathrm{ml}$, an Amicon cell model 202 with filter PM 10 (permeable to molecular sizes of less than $10000 \mathrm{Dal}$ ) was used until the final volume was $12 \mathrm{ml}$. These concentrated samples were analysed on a $320 \mathrm{ml}$ gel filtration column $(65 \mathrm{~cm} \times 2.5 \mathrm{~cm})$ with Sephadex G-100 (Pharmacia). The column was in equilibrium with a $0 \cdot 10 \mathrm{M}$-potassium phosphate buffer, $\mathrm{pH} 6 \cdot 4$, and the flow was maintained at $26 \mathrm{ml} \mathrm{h}^{-1}$ using a peristaltic pump Perpex 10200 (LKB). Fraction volumes were $5.2 \mathrm{ml}$. To avoid possible contamination of proteases in columns, purification steps were always performed with Db1121 first, followed by Db1120 and last Db11. Active fractions were pooled and concentrated to $5 \mathrm{ml}$ simultaneously as the buffer was changed to $0.02 \mathrm{M}-\mathrm{Tris} / \mathrm{HCl} \mathrm{pH} 7 \cdot 8$, using the Amicon cell 202 . Ion exchange chromatography was performed on a $7.7 \mathrm{ml}$ column $(5.0 \mathrm{~cm} \times 1.4 \mathrm{~cm})$ with DEAE-Sepharose Cl-6B (Pharmacia) equilibrated with $0.02 \mathrm{M}-\mathrm{Tris} / \mathrm{HCl} \mathrm{pH} \mathrm{7.8}$. After application of samples, the column was washed three times with the starting buffer and then eluted with a gradient $0-0.25 \mathrm{M}-\mathrm{NaCl}(150 \mathrm{ml})$, elution-time $3.5 \mathrm{~h}$. Protease-active fractions were pooled and stored at $-20^{\circ} \mathrm{C}$. All filtrates from the Amicon cell were checked for proteolytic activity. No activity passed through the membrane.

Chromatofocusing. Pooled samples (1.0 ml and $1.5 \mathrm{ml}$, respectively) of the largest peaks of Proteases 1 and $2 \mathrm{from}$ DEAE-Sepharose chromatography were loaded on a $10 \mathrm{ml}$ chromatofocusing column $(35 \mathrm{~cm} \times 0.60 \mathrm{~cm})$ with Polybuffer 74 (Pharmacia).

Assay for proteolytic activity. The procedure of Rinderknecht et al. (1968) was modified as follows. A sample was made up to $5 \mathrm{ml}$ with $0.05 \mathrm{M}$-Tris/ $\mathrm{HCl}$ pH 7.9 buffer solution. Hide Powder ( $20 \mathrm{mg}$; Sigma) was added to each tube and the reaction mixture incubated at $37^{\circ} \mathrm{C}$ for $2 \mathrm{~h}$. The tubes were then centrifuged for $20 \mathrm{~min}$ at $3250 \mathrm{~g}$. The absorbance of the clear supernatant was measured at $595 \mathrm{~nm}$ against a blank to which no enzyme was added. An increase in absorbance of $0 \cdot 10$ during $2 \mathrm{~h}$ incubation at $37^{\circ} \mathrm{C}$ was defined as one unit of proteolytic activity. Proteolytic activity in electrophoretograms was detected according to Westergaard et al. (1980) after separation of native proteins by PAGE.

Test with different inhibitors. Inhibitors, at a final concentration of $1 \mathrm{mM}$, were mixed with $50 \mu \mathrm{l}$ enzyme and $4.85 \mathrm{ml} \mathrm{Tris} / \mathrm{HCl}$ buffer. The mixture was then preincubated at $37^{\circ} \mathrm{C}$ for $1 \mathrm{~h}$ and finally assayed for proteolytic activity as above, except that the incubation time was $20 \mathrm{~min}$.

Assay for protein. Protein was determined by the Lowry method except in the chromatofocusing experiment when we used the procedure of Bradford (1976).

Analytical PAGE. Electrophoresis of native proteins was performed essentially according to Maizel (1971), using $7.5 \%(\mathrm{w} / \mathrm{v})$ gels and Pharmacia apparatus GE-4. SDS-PAGE of denatured proteins was carried out in 7.5\% (w/v) gels, first according to Laemmli (1970), later as described by Neville (1971). Acidic electrophoresis was performed according to Hultmark et al. (1980) with an acrylamide/bisacrylamide ratio of $60: 0 \cdot 8$. All gels were fixed in $45 \%$ ethanol $/ 45 \% \mathrm{H}_{2} \mathrm{O} / 10 \%$ acetic acid, stained with Coomassie brilliant blue $\mathrm{R}$ in $7.5 \%$ acetic acid, and destained in $7.5 \%$ acetic acid.

\section{RESULTS}

\section{Comparisons of parental strain and mutants isolated}

We first investigated our strains of $S$. marcescens for survival in IH from Cecropia pupae. About 4000 cells of each strain were incubated with $90 \%$ IH at $37^{\circ} \mathrm{C}$ for $2 \mathrm{~h}$. At the intervals indicated, $5 \mu \mathrm{l}$ samples were withdrawn for viable counts (Fig. 1). The survival values showed that our triple mutant Db1140 (lacking two proteases and resistant to the phage) was more sensitive to IH than our spontaneous phage-resistant mutant $\mathrm{Db} 1109$, but both were much more sensitive than our double protease-negative, phage-sensitive mutant Db1121. Thus, phage resistance decreased resistance to Cecropia immunity more than the absence of proteolytic enzymes.

When about 5 cells per fly were injected into the Drosophila haemocoel, the triple mutant Db1140 was found to be the least virulent strain because it did not differ from the control (Fig. 2). Strains Db11 and Db1121 (both sensitive to $\phi \mathrm{J}$ ) were highly virulent and killed all flies within $24 \mathrm{~h}$. Thus, phage resistance decreased the virulence independently of the proteases. If the flies were immunized in advance with $E$. cloacae, the wild-type Dbll killed the flies a few hours sooner than did mutant Db1 121, but both strains were also highly virulent for immunized flies.

In order to induce proteases, washed cells of the parental strain $\mathrm{Db} 11$, the phage-resistant mutant Db1 109 and the two protease-deficient mutants Db1120 and Db1121 were inoculated 


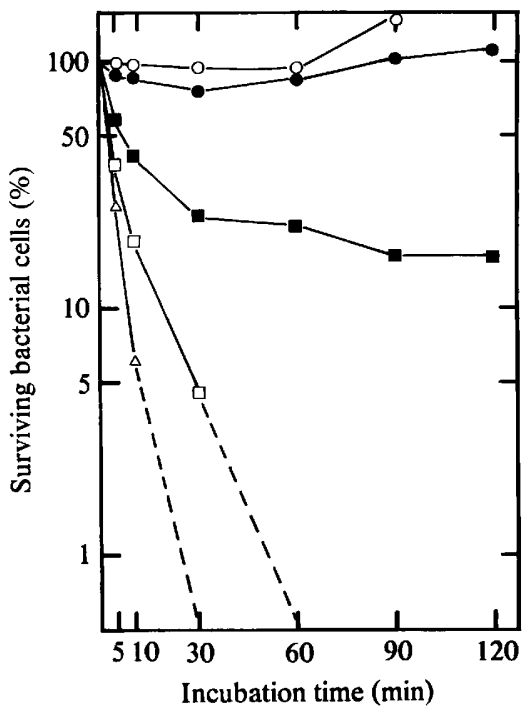

Fig. 1

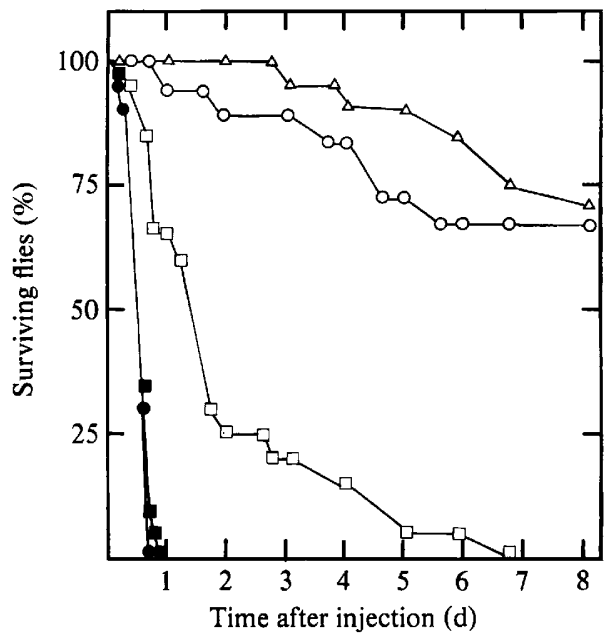

Fig. 2

Fig. 1. Susceptibility of different strains of $S$. marcescens to immune haemolymph from Cecropia at $37^{\circ} \mathrm{C}$. , Db11, parental strain; $\square$, Db1121, protease-deficient mutant; $\square$, Db1109, phage-resistant mutant; $\triangle$, Db1140, protease-deficient and phage-resistant mutant. The relationship between the strains is given in Table 1 . The incubation mixture $(50 \mu \mathrm{l})$ contained $3.2 \times 10^{3}$ to $5.8 \times 10^{3}$ bacteria. The buffer used was 0.01 M-potassium phosphate, $\mathrm{pH} 6.4$ and the haemolymph concentration was $90 \%$. Normal haemolymph incubated with strain Dbll was the control (O).

Fig. 2. Survival of Drosophila flies after injection with about five viable cells of different Serratia strains., Db1 1, parental strain; $\square$, Db1 121, protease-deficient mutant; $\square$, Db1 109, phage-resistant mutant; $\triangle$, Dbl140, protease-deficient and phage-resistant mutant. Flies injected with Ringer's solution were the control $(O)$. The relationship between the strains is given in Table 1 .

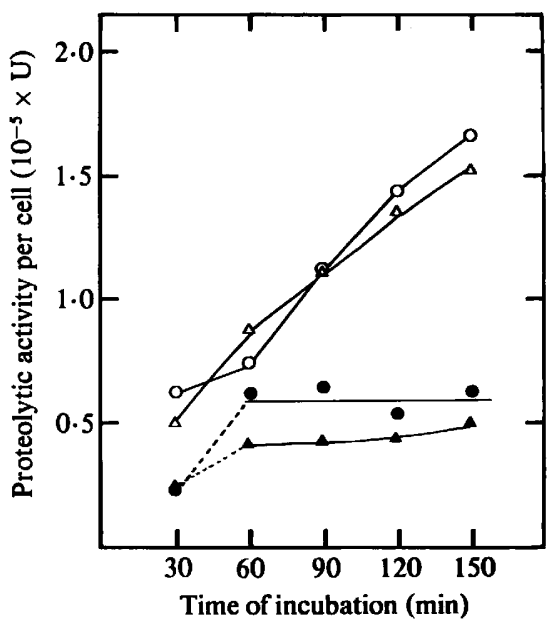

Fig. 3. Induction of protease activity per living cell in a C-A medium without glycerol but supplemented with $5 \%$ gelatin and $10 \%$ normal Cecropia haemolymph. $O$, Db11, parental strain; $\triangle$, Db1109, resistant to phage $\phi \mathrm{J} ; \operatorname{Db} 1120(\mathbf{A})$ and Db1121 (O), the protease-deficient mutants.

into a C-A medium (Bromke \& Hammel, 1979) without glycerol, but supplemented with 5\% gelatin and $10 \%$ normal Cecropia haemolymph. Plotting of proteolytic activity per living cell against time of growth, showed that the gelatin haemolymph medium induced protease synthesis in strains Db11 and Db1 109, while the double protease-negative mutants Db1120 and 

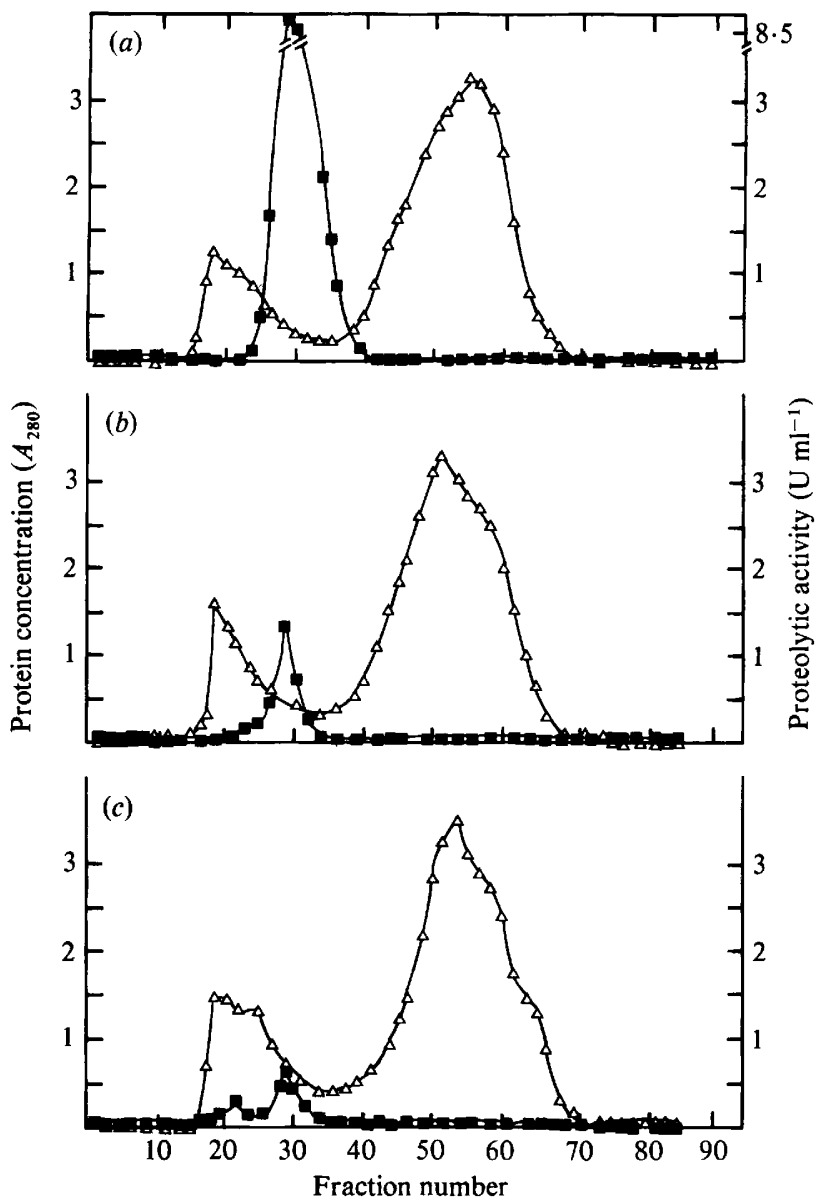

Fig. 4. Gel filtration of culture supernatants from the parental strain, Db11 (a) and two proteasedeficient mutants, Db1120 (b) and Db1121 (c). A column $(65 \mathrm{~cm} \times 2.5 \mathrm{~cm})$ with Sephadex G-100 was equilibrated with $0.1 \mathrm{M}$-potassium phosphate buffer, $\mathrm{pH} 6.4$ and loaded with $12 \mathrm{ml}$ concentrated supernatant. Flow rates were $26 \mathrm{ml} \mathrm{h}^{-1}$ and fraction volumes were $5.2 \mathrm{ml}$. Fractions were assayed for proteolytic activity $(\square)$ and $A_{280}(\triangle)$ was determined. The active fractions were pooled.

Db1121 gave only a very small response (Fig. 3). The absence of carbohydrates in this 'gelatin haemolymph medium' minimizes the catabolite repression of protease production, earlier investigated (Bromke \& Hammel, 1979). The first points for mutants Db1120 and Db1121 in Fig. 3 (at $t=30$ ) are just above the level of detection. When strain Db11 was grown in LB medium on a rotatory shaker for $7 \mathrm{~d}$ at $37^{\circ} \mathrm{C}$, proteolytic enzymes reached a plateau which was maintained for $6 \mathrm{~d}$. Therefore cultures for protease purification were harvested after $4 \mathrm{~d}$.

\section{Purification of proteolytic factors}

We have used two different purification schemes. Method 1 consisted of gel filtration on G-100, DEAE-chromatography and chromatofocusing. Method 2 used gel filtration on G-50 Superfine, DEAE-chromatography and gel filtration on S-200. In both cases, fractions had to be concentrated by ultrafiltration which was also used to change buffers when needed.

The areas below peaks of proteolytic activity in gel filtration of concentrated culture filtrates gave an estimate of the protease production of strains Db11, Db1120 and Db1121 (Fig. 4). Expressed as a percentage of the parental strain $\mathrm{Dbl1}$, the amounts of proteolytic activities were $12 \%$ in mutant Db1 120 and $7.9 \%$ in Db1121, respectively. This first gel filtration step effectively removes the brown material (fractions $40-70$ in Fig. 4) originating from the growth medium. 

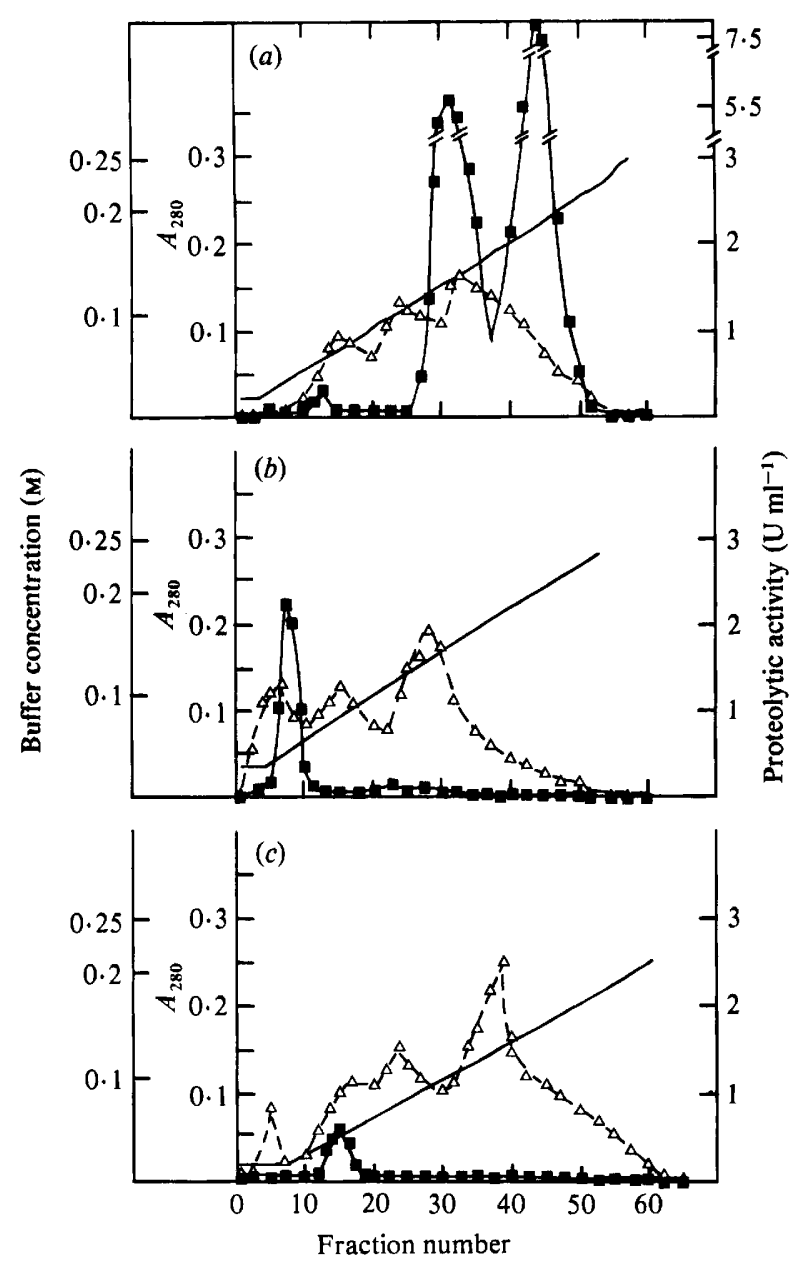

Fig. 5. Anion exchange chromatography of pooled proteolytic peaks from gel filtration (Fig. 4) of material originating from the parental strain, Db11 (a), and two protease-deficient mutants, Db1 $120(b)$ and Db1121 (c). A column $(5.0 \mathrm{~cm} \times 1.4 \mathrm{~cm})$ with DEAE-Sepharose CL-6B was washed with 0.02 MTris/ $/ \mathrm{HCl}, \mathrm{pH} 7.8$ and then eluted with a linear gradient of $\mathrm{NaCl}$ increasing to $0.25 \mathrm{M}$. $\square$, Proteolytic activity; $\triangle, A_{280} ;-$, buffer concentration.

Chromatography on DEAE-Sepharose showed that the protease activity in the parental strain Db11 consists of at least three components (Fig. 5). The largest peak is hereafter referred to as Protease 1 and the small one appearing early in the elution, Protease 2 . The middle peak is probably an active cleavage product of Protease 2 but this proteolytic component has not been investigated further. Mutants Db1120 and Db1121 give only Protease 2 and the amount of enzyme is clearly lower in the double mutant Db1121. Peaks of Proteases 1 and 2 were always eluted at the same intervals of the gradient.

In an attempt to obtain further purification, Proteases 1 and 2 were subjected to chromatofocusing. This step gave an additional purification of about 8 and more than 25 times for Proteases 1 and 2, respectively, but autodigestion was very evident. Unfortunately, the degree of purification could not be judged by SDS-PAGE due to the small amount of the material obtained (70-80 $\left.\mathrm{ng} \mathrm{m}^{-1}\right)$ and/or the buffer system used in chromatofocusing. Furthermore, $\mathrm{LD}_{50}$ of the samples could not be determined because the Polybuffer itself was toxic to the flies. Thus, method 2 had to be used for further comparisons, especially for toxicity tests.

About $3 \%$ of the proteolytic activity of the sum of Proteases 1 and 2 did not adsorb to either 

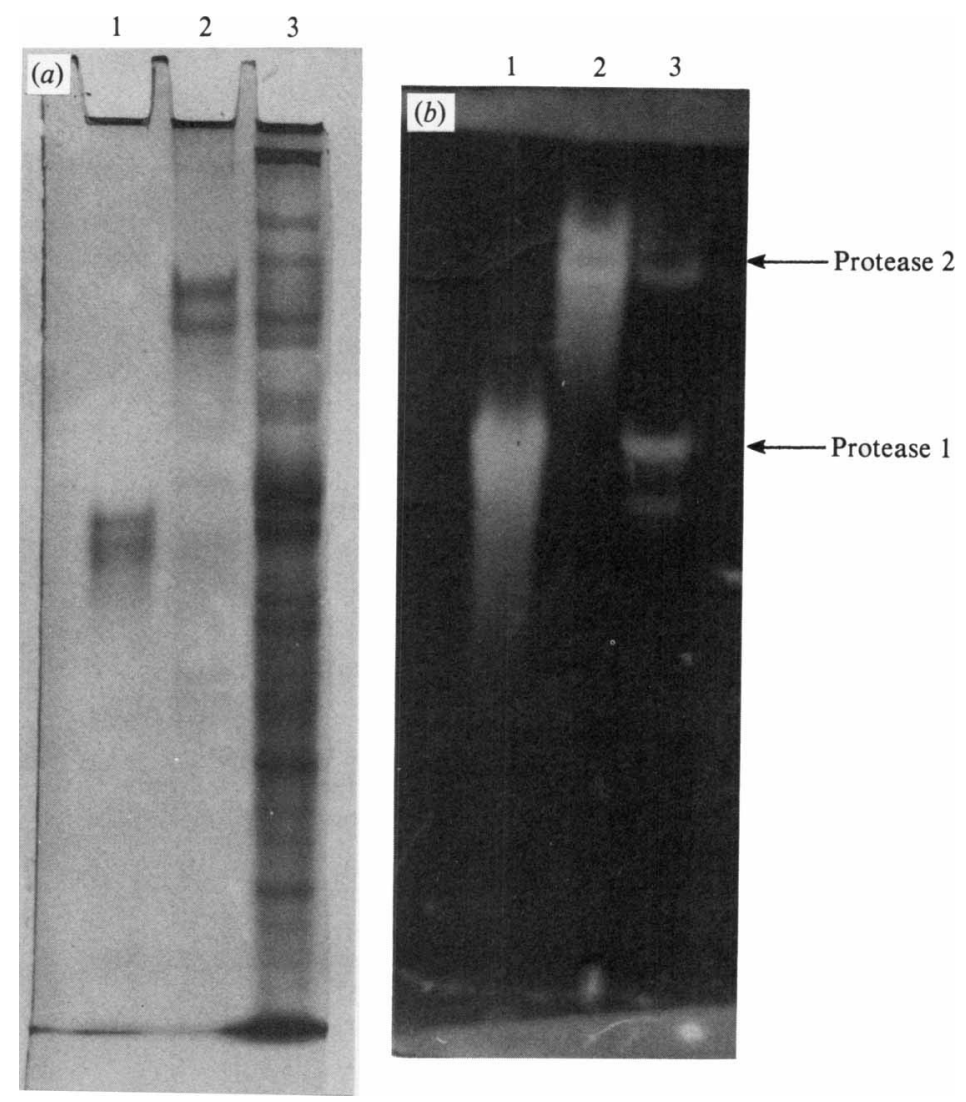

Fig. 6. Separation of native proteins by PAGE. (a) Lane 1, Protease 1; lane 2, Protease 2 and lane 3, concentrated supernatant of a Db1 1 culture. (b) Replica plating on zymogram of the same gel to indicate bands with proteolytic activity.

Table 2. Properties of protease fractions obtained by method 2

Protein concentration was determined by the Lowry method. Molecular weights were determined on $7 \cdot 5 \%$ SDS-PAGE according to Laemmli (1970).

\begin{tabular}{lccc}
\multicolumn{1}{c}{ Properties } & Protease 1 & Protease 2 & RAC fraction \\
$A_{280}$ & 0.702 & 1.105 & $11 \cdot 8$ \\
Protein concn $\left(\mathrm{mg} \mathrm{ml}^{-1}\right)$ & $1 \cdot 0$ & 0.40 & ND \\
Proteolytic activity $\left(\mathrm{U} \mathrm{ml}^{-1}\right)$ & 5675 & 3130 & 295 \\
Specific activity $\left(\mathrm{U} \mathrm{mg}^{-1}\right)$ & 5675 & 7825 & ND \\
Mol. wt & $55 \times 10^{3}$ & $78 \times 10^{3}$ & ND
\end{tabular}

ND, Not determined.

CM-Sepharose or DEAE-Sepharose in equilibrium with $0.005 \mathrm{M}$-potassium phosphate buffer, $\mathrm{pH} 7 \cdot 1$. This material, 'remaining active concentrate' (RAC), is not highly purified but it was concentrated and investigated for action on $\mathbf{I H}$.

\section{Properties of purified proteases}

Figure 6(a) shows a polyacrylamide gel of native Proteases 1 and 2 purified by method 2 (lanes 1 and 2) and a concentrated culture supernatant of strain Db11 (lane 3). A replica-plating of the same gel on a zymogram to indicate bands with proteolytic activity is shown in Fig. $6(b)$. Regions of Protease 1 and 2 are indicated. Toxicity tests, molecular weights, specific activities and other properties are summarized in Table 2. 
Table 3. Production of bacteriocin at different temperatures by protease-deficient mutants of $S$. marcescens

The strains were spread on LA plates in $2.5 \mathrm{ml}$ soft agar $(0.7 \%$ agar) at a density of about 100 cells per plate. The plates were then overlaid with a second layer of soft agar and incubated at different temperatures overnight. After $24 \mathrm{~h}$, the plates were exposed to $\mathrm{CHCl}_{3}$ vapour for $1 \mathrm{~min}$ and then overlaid with $2.5 \mathrm{ml}$ soft agar containing about $5 \times 10^{7}$ living cells of $E$. coli D21f2 (a heptose-less LPS mutant). Finally, the plates were incubated overnight once more in the same temperatures. Colonies of Serratia producing clear zones in the layer of $E$. coli are indicated by + and absence of a zone by - .

\begin{tabular}{cccc} 
Temperature & \multicolumn{3}{c}{$\begin{array}{c}\text { Bacteriocin production } \\
\text { by colonies of strain: }\end{array}$} \\
\cline { 2 - 4 }$\left({ }^{\circ} \mathrm{C}\right)$ & Db11 & Db1120 & Db1121 \\
25 & - & + & + \\
30 & - & + & + \\
37 & - & + & + \\
41 & + & + & +
\end{tabular}

Table 4. Effects of inhibitors on partly purified Proteases 1 and 2

\begin{tabular}{lcc}
\multicolumn{1}{c}{ Inhibitor* } & \multicolumn{2}{c}{$\begin{array}{c}\text { Proteolytic activity } \\
(\% \text { of control) }\end{array}$} \\
\cline { 2 - 3 } Protease 1 & Protease 2 \\
Control & 100 & 100 \\
Iodoacetamide & 98 & 92 \\
Soy bean trypsin inhibitor & 96 & 96 \\
EGTA & 64 & 98 \\
EDTA & 57 & 90 \\
PMSF & 43 & 37 \\
41 ${ }^{\circ}$ C $\dagger$ & 27 & 49
\end{tabular}

\footnotetext{
* Inhibitors were used at a final concentration of $1 \mathrm{mM}$ in the assay, except for soy bean trypsin inhibitor (0.5 mg; Boehringer Mannheim). Iodoacetamide and PMSF were first dissolved in $0.10 \mathrm{ml}$ of $95 \%$ ethanol. $\dagger$ Before the assay, undiluted enzyme was preincubated for $30 \mathrm{~min}$ at $37^{\circ} \mathrm{C}$ as a control $(100 \%$ activity) and at $41^{\circ} \mathrm{C}$.
}

Foulds \& Shemin (1969) described a temperature-sensitive factor which inactivated a bacteriocin produced by Serratia. To identify this factor, strains Db11, Db1120 and Db1121 were incubated at different temperatures, then overlaid with Escherichia coli D21f 2 as indicator bacteria and finally incubated overnight at the same temperatures (Table 3 ). In the parental strain $\mathrm{Dbl1}$, bacteriocin was detected only at $41^{\circ} \mathrm{C}$. Both of the protease mutants allowed production of bacteriocin at all tested temperatures.

Partly purified preparations of Proteases 1 and 2 were tested for effects of inhibitors (Table 4). EDTA and EGTA decreased the activity to about $60 \%$ of the control for Protease 1 , but showed only a minor effect on Protease 2. Phenylmethylsulphonyl fluoride (PMSF) inhibited both proteases significantly, while there were no effects with soy bean trypsin inhibitor or iodoacetamide.

\section{Protease digestion of Cecropia immune proteins}

When examined by SDS-PAGE, Proteases 1 and 2 degraded immune protein P5 while most other bands were preserved (Fig. 7). The RAC fraction showed a clotting effect in agreement with an observation by Kučera \& Lysenko (1977).

In another experiment, different dilutions of the proteases were incubated with IH for $30 \mathrm{~min}$ at $37^{\circ} \mathrm{C}$. Afterwards samples were spotted on gels and fractionated by acid-PAGE in combination with a bioassay for cecropins (Fig. 8). Proteases 1 and 2 both destroyed cecropins as well as P5 quite effectively. In contrast the RAC fraction preferentially acted on the cecropins. 


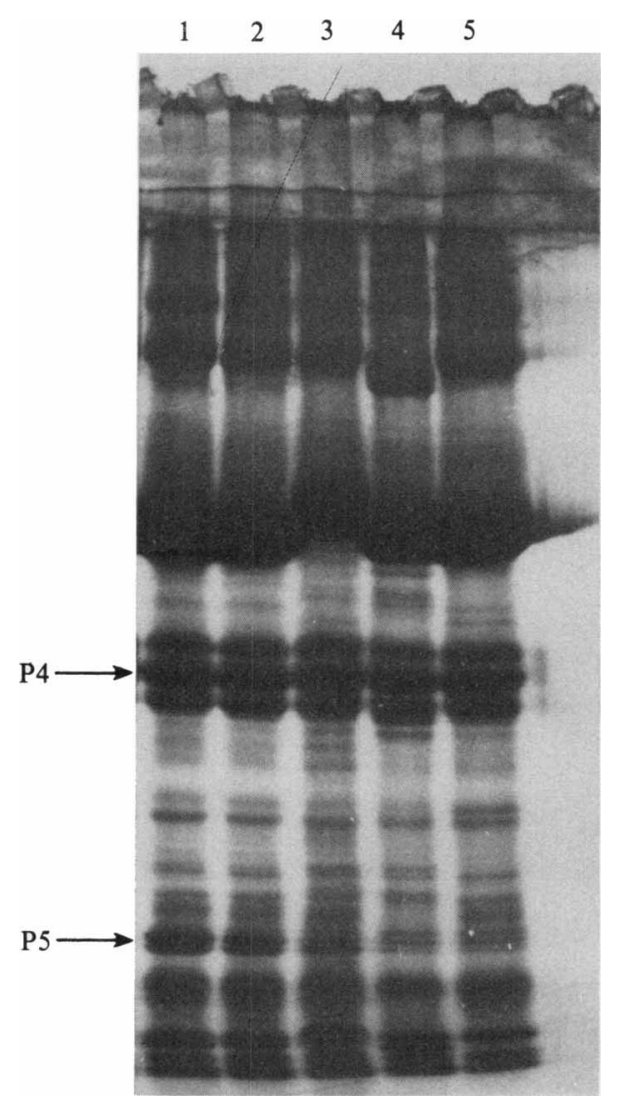

Fig. 7. Effects of partially purified proteases on immune haemolymph (IH) of Cecropia. SDS-PAGE on a $7.5 \%-15 \%$ gradient gel with a $4.5 \%$ stacking gel, using a discontinuous buffer system. All samples contain IH. Lanes 1 and 2 are controls without and with $90 \mathrm{~min}$ incubation with $0.02 \mathrm{M}-\mathrm{Tris} / \mathrm{HCl}$ buffer, pH 7.8 (proportions 1 part IH : 2 parts buffer); lane 3 , IH with RAC fraction $(1: 2)$; lane 4 , IH with Protease $2(1: 2)$ and lane 5, IH with Protease 1 (1:2). P4 and P5 are immune proteins.

\section{DISCUSSION}

Serratia marcescens is a common insect pathogen having at least four different proteases (Grimont \& Grimont, 1978). We have found our strain of Serratia to produce three different protease fractions: Proteases 1 and 2 and the RAC fraction. From the chromatograms (Fig. 5) we conclude that mutant Db1 120 is lacking Protease 1. In this strain, the peak for Protease 2 was significantly larger than in the parental strain Db11, a finding which indicates that during our growth and preparative work Protease 1 may degrade Protease 2. The difference between mutant Db1120 and the double mutant Db1121 seems only to be a reduced level of Protease 2 . The (over-all) protease activity in the parental strain Db11 was inducible in a medium with Cecropia haemolymph (Fig. 3). Under the same conditions there was only a short period of increase in both Db1120 and Db1121. This indicates that strains Db1120 and Db1121 are mutants affected in the regulation of Protease 1.

One of our proteases could be identical to the bacteriocin-destroying factor described by Foulds \& Shemin (1969). Table 3 shows that production of bacteriocin was detected by our parental strain Db11 only at $41^{\circ} \mathrm{C}$ and at all temperatures by mutants Db1120 and Db1121. In addition, the proteolytic activity of the enzymes was decreased when they were incubated at $41{ }^{\circ} \mathrm{C}$ for $30 \mathrm{~min}$. Since the two mutants lack Protease 1, we assume that this protease is the temperature-sensitive factor of Foulds \& Shemin (1969). 

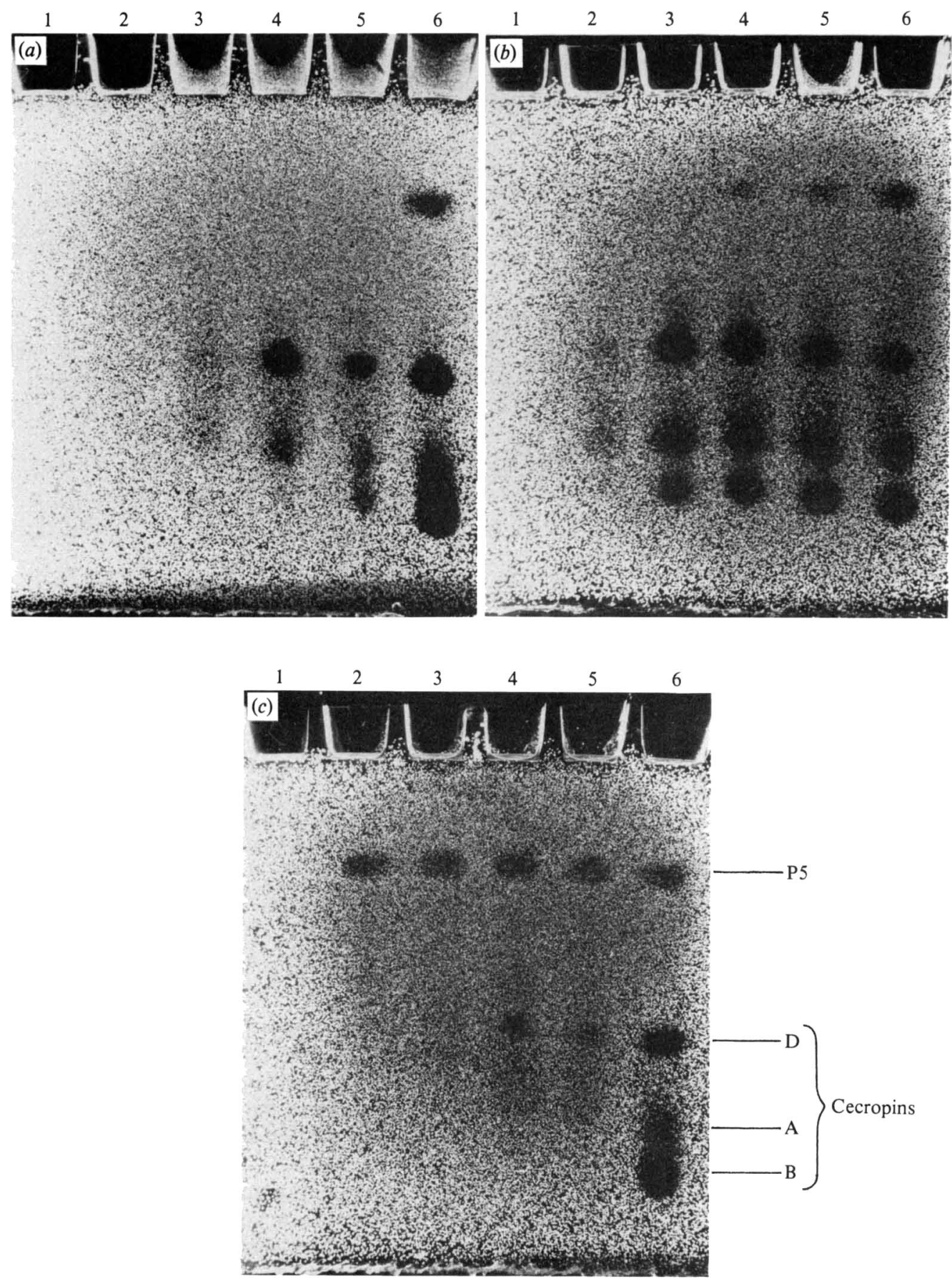

Fig. 8. Effects of partially purified proteases on the cecropins. IH was incubated with different amounts of proteolytic enzymes for $30 \mathrm{~min}$ at $37^{\circ} \mathrm{C}$. Afterwards the samples were examined by electrophoresis in $15 \%$ polyacrylamide gels, $\mathrm{pH} 4$. Gels contained samples with $(a)$ Protease $1,(b)$ Protease 2 and $(c)$ the RAC fraction. Lane 1 contained one part of $1 \mathrm{H}$ mixed with one part of undiluted enzyme; lanes 2-5 contained twofold dilutions of the respective proteases. Lane 6 contained a control with one part IH added toone part buffer $(0.02 \mathrm{M}$-Tris/ $\mathrm{HCl}, \mathrm{pH} 7.8)$. Pointersindicatedifferent immune proteins. 
Two groups have reported highly purified preparations of a protease from $S$. marcescens ATCC 25419 (Braun \& Schmitz, 1980; Decedue et al., 1979). Starting from $S$. marcescens strain BG, a similar protease was purified by Lyerly \& Kreger (1979). These enzymes were reported to be metalloproteases inactivated by EDTA. Gorini (1950) found that for several bacterial proteases calcium was essential for function and stability. This was also confirmed by Castañeda-Agulló (1956). For Protease 2 we observed no effect with EDTA or EGTA (Table 4). With Protease 1, EDTA gave a reduction believed to reflect a stabilizing effect of a divalent metal ion. Taken together, we conclude that Proteases 1 and 2 differ from the metalloenzymes isolated from strains ATCC 25419 and BG. Autodigestion of highly purified proteolytic enzymes from Serratia was encountered in these studies as well as in our own work.

The biological role of the proteases in our strains was studied both by comparing two different protease-deficient mutants and by investigations of the toxicity of partly purified enzyme preparations. The $\mathrm{LD}_{50}$ for both Protease 1 and 2 was around $0.5 \mathrm{ng}$ per Drosophila fly. In addition, incubation of partly purified proteases with Cecropia IH (Figs 7 and 8) showed that the enzymes specifically destroyed cecropins, the components in $\mathrm{IH}$ which are acting against Gram-negative bacteria (Steiner et al., 1981). Two factors that counteract the insect immune response have earlier been described; one from Bacillus thuringiensis (Siden et al., 1979) and one from a nematode which needs a symbiotic bacterium (Götz et al., 1981). In both cases these factors were shown to degrade cecropins in insects. Our proteases here show the same specificity in vitro.

Our in vivo experiments with Drosophila (Fig. 2) clearly show that the protease-negative double mutant Db1121 was almost as virulent as our parental strain Db11. Thus, we have to conclude that neither Protease 1 nor 2 contributes to the lethal effects of our Serratia in these injection experiments. We have used feeding experiments according to Flyg et al. (1980), but failed to obtain conclusive results concerning a role for the proteases.

We have used mutagens to obtain strains Db1120 and Db1121 and we must expect them to carry several undetected mutations. However, it is difficult to imagine how an undetected mutation could account for the fact that our two protease-negative mutants were always more resistant to Cecropia immunity than were the two spontaneous phage-resistant mutants Db1109 and Db1140 (Fig. 1). Thus, as an overall conclusion, our results demonstrate that, under our assay conditions, passive resistance to immunity is a more important virulence factor than the production of proteases even though they show a preference for cecropins.

We are grateful to Professor Hans G. Boman who helped us in the preparation of the manuscript; C.F. thanks Dr James Ellerson for helpful discussions. The work was supported by The Swedish Natural Science Research Council through grants BU 2453- 100, 102 and 109.

\section{REFERENCES}

BERTANI, G. (1951). Studies on lysogenesis. I. The mode of phage liberation by lysogenic Escherichia coli. Journal of Bacteriology 62, 293-300.

Blazevic, D. J. (1980). Section I. Taxonomy, isolation and identification of Serratia. In The Genus Serratia, pp. 3-13. Edited by A. von Graevenitz \& S. J. Rubin. Boca Raton, Florida: CRC Press.

Boman, H. G. \& Steiner, H. (1981). Humoral immunity in Cecropia pupae. Current Topics in Microbiology and Immunology 94/95, 75-91.

Boman, H. G., Nilsson, I. \& Rasmuson, B. (1972). Inducible antibacterial defence system in Drosophila. Nature, London 237, 232-235.

Boman, H. G., Nilsson-Faye, I., Paul, K. \& RASMUSON, T. (1974). Insect Immunity. I. Characteristics of an inducible cell-free antibacterial reaction in hemolymph of Samia cynthia pupae. Infection and Immunity 10, 136-145.
BRADFORD, M. M. (1976). A rapid and sensitive method for the quantitation of microgram quantities of protein utilizing the principle of protein-dye binding. Analytical Biochemistry 72, 248-254.

Braun, V. \& Schmitz, G. (1980). Excretion of a protease by Serratia marcescens. Archives of Microbiology 124, 55-61.

Bromke, B. J. \& HAMmel, J. M. (1979). Regulation of extracellular protease formation by Serratia marcescens. Canadian Journal of Microbiology 25, 47-52.

Castañeda-Agulló, M. (1956). Studies on the biosynthesis of extracellular proteases by bacteria. I. Serratia marcescens. Synthetic and gelatin media. Journal of General Physiology 39, 369-375.

Decedue, C. J., Broussard II, E. A., Larson, A. D. \& Braymer, H. D. (1979). Purification and characterization of the extracellular proteinase of Serratia marcescens. Biochimica et biophysica acta 569, 293301 . 
Flyg, C., Kenne, K. \& Boman, H. G. (1980). Insect pathogenic properties of Serratia marcescens: phageresistant mutants with a decreased resistance to Cecropia immunity and a decreased virulence to Drosophila. Journal of General Microbiology 120, 173181.

Foulds, J. D. \& Shemin, D. (1969). Concomitant synthesis of bacteriocin and bacteriocin inactivator from Serratia marcescens. Journal of Bacteriology 99 , 661-666.

GoRINI, L. (1950). Le rôle du calcium dans l'activité et la stabilité de quelques protéinases bactériennes. Biochimica et biophysica acta 6, 237-255.

GöTz, P., BomaN, A. \& Boman, H. G. (1981). Interactions between insect immunity and an insectpathogenic nematode with symbiotic bacteria. Proceedings of the Royal Society B212, 333350.

Grimont, P. A. D. \& GRIMONT, F. (1978). The genus Serratia. Annual Review of Microbiology 32, 221-248.

Hultmark, D., Steiner, H., Rasmuson, T. \& Boman, H. G. (1980). Insect immunity. VI. Purification and properties of three inducible bactericidal proteins from hemolymph of immunized pupae of Hyalophora cecropia. European Journal of Biochemistry 106, 7-16.

KAŠKA, A. (1976). The toxicity of extracellular proteases of the bacterium Serratia marcescens for larvae of the greater wax moth Galleria mellonella. Journal of Invertebrate Pathology 27, 271.

KUČERA, M. \& LYSENKO, O. (1977). The mechanism of pathogenicity of Pseudomonas aeruginosa: milkclotting activity of the proteolytic enzymes toxic for Galleria mellonella larvae. Journal of Invertebrate Pathology 29, 388-389.

LAEMMLI, U. K. (1970). Cleavage of structural proteins during the assembly of the head of bacteriophage T4. Nature, London 227, 680-685.

Lyerly, D. \& KReger, A. (1979). Purification and characterization of a Serratia marcescens metalloprotease. Infection and Immunity 24, 411-421.

MaIzel, J. V., JR (1971). Polyacrylamide gel electrophoresis of viral proteins. Methods in Virology 5, 179-246.

Miyata, K., Maejima, K., Tomoda, K. \& Isono, M. (1970). Serratia protease. Part I. Purification and general properties of the enzyme. Agricultural and Biological Chemistry 34, 310-318.

Neville, D. M. JR (1971). Molecular weight determination of protein-dodecyl-sulfate complexes by gel electrophoresis in a discontinuous system. Journal of Biological Chemistry 246, 6328-6334.

Ourth, D. D. \& Smalley, D. L. (1980). Phagocytic and humoral immunity of the adult cotton boll weevil, Anthonomus grandis (Coleoptera: Curculionidae), to Serratia marcescens. Journal of Invertebrate Pathology 36, 104-112.

Poinar, G. O., JR, Wassink, H. J. M., LeegwaterVAN DER LINDEN, M. E. \& VAN DER GeEsT, L. P. S. (1979). Serratia marcescens as a pathogen of tsetse flies. Acta tropica 36, 223-227.

Rinderknecht, H., Geokas, M. C., Silverman, P. \& HAVERBaCK, B. J. (1968). A new ultrasensitive method for the determination of proteolytic activity. Clinica chimica acta 21, 197-203.

Sidén, I., Dalhammar, G., Telander, B., Boman, H. G. \& SOMMER VILle, H. (1979). Virulence factors in Bacillus thuringiensis: purifications and properties of a protein inhibitor of immunity in insects. Journal of General Microbiology 114, 45-52.

Steiner, H., HultMark, D., ENGSTRÖm, A., BenNich, H. \& Boman, H. G. (1981). Sequence and specificity of two antibacterial proteins involved in insect immunity. Nature, London 292, 246-248.

Westergaard, J. L., Hackbarth, C., Treuhaft, M. W. \& RoBerts, R. C. (1980). Detection of proteinases in electrophoretograms of complex mixtures. Journal of Immunological Methods 34, 167-175. 